\title{
Unplanned Hospital Readmission and Visit to the Emergency Room in the First Thirty Days after Head and Neck Surgery: A Prospective, Single-center Study
}

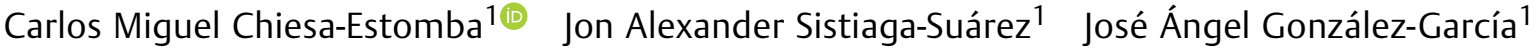 \\ Ekhiñe Larruscain Sarasola ${ }^{1}$ Ariadna Valldeperes Vilanova ${ }^{1} \quad$ Xabier Altuna ${ }^{1}$ \\ ${ }^{1}$ Department of Otorhinolaryngology - Head \& Neck Surgery, \\ Hospital Universitario Donostia, San Sebastian - Donosti, Guipuzkoa \\ - Basque, Spain \\ Int Arch Otorhinolaryngol 2022;26(1):e103-e110. \\ Address for correspondence Carlos Miguel Chiesa-Estomba, MD, \\ Department of Otorhinolaryngology - Head and Neck Surgery. \\ Hospital Universitario Donostia, Calle General Lertsundi, \#6, 5to \\ Izquierda,Izquierda. CP. 20007, San Sebastian- Donosti, España \\ (e-mail: chiesaestomba86@gmail.com).
}

\begin{abstract}
Keywords

- head

- neck

- surgery

- complications

Introduction Head and neck surgery remains a complex field; the patients can suffer important functional or life-threating complications after treatment that need unplanned readmissions, increasing the cost related to the treatment.

Objective To evaluate the incidence risk factors and causes associated with 30-day unplanned hospital readmission and visit to the emergency room (ER) after surgery for head and neck cancer.

Methods Prospective, longitudinal, nonrandomized study.

Results A total of 834 patients were included, 726 in the major surgery group and 108 in the minor surgery group. The 30-day readmission rate for all causes was of 7,9\% for the patients treated by a major surgery and of $0 \%$ for the patients treated in the outpatient clinic for minor procedures, to a total readmission rate of $6,8 \%$. The rate of visit to the emergency room for all causes in the first 30 days was of $14 \%$ for the patients treated by a major surgery and of $2,7 \%$ for the patients treated in the outpatient clinic. Conclusion Major surgery, the American Society of Anesthesiologists (ASA) status and type of wound are conditions related to unplanned readmission or visit to the ER in the first 30 day after discharge. The most commonly associated causes are infections or wound complications. An evidence-based risk stratification of the patients can be important to improve decision-making and resource utilization. An educational strategy can provide possible ways to improve the rate of readmission and reduce the amount of money expended by healthcare systems.
\end{abstract}

received

March 16, 2020

accepted

February 15, 2021

published online

August 4, 2021
DOI https://doi.org/

10.1055/s-0041-1730340. ISSN 1809-9777. (c) 2021. Fundação Otorrinolaringologia. All rights reserved.

This is an open access article published by Thieme under the terms of the Creative Commons Attribution-NonDerivative-NonCommercial-License, permitting copying and reproduction so long as the original work is given appropriate credit. Contents may not be used for commercial purposes, or adapted, remixed, transformed or built upon. (https://creativecommons.org/ licenses/by-nc-nd/4.0/)

Thieme Revinter Publicações Ltda., Rua do Matoso 170, Rio de Janeiro, RJ, CEP 20270-135, Brazil 


\section{Introduction}

Head and neck surgery remains a complex field; patients with these kinds of pathologies can suffer significant functional or life-threating complications after treatment that need unplanned readmissions increasing the cost related to the treatment. In 2014, the United States Healthcare system spent US\$3 trillion and, to try to decrease this, a hospital readmissions reduction program was applied to evaluate the quality of care and the financial implications. ${ }^{1}$

The causes of 30-day readmission for surgical patients differ from those of medical patients; nonetheless, readmissions after surgical procedures can also be secondary to a medical condition or to complications or comorbidity exacerbated by the procedure itself. ${ }^{2-4}$

Prior studies performed in North American otorhinolaryngology - head and neck surgery departments seeking to identify risk factors for unplanned hospital readmission among patients undergoing otolaryngology procedures reported rates of hospital readmission ranging from 3.1 to $7.3 \%{ }^{2,4-9}$ These studies identified a strong association between the occurrence of postoperative complications and unplanned 30-day readmissions. ${ }^{2,10}$ In another study that included 1,058 patients undergoing ear, nose, and throat (ENT) surgery, Graboyes et al. found that patients who experienced a complication during or after their index hospitalization were 11.9 times more likely to be readmitted to the hospital within 30 days than patients without complications. ${ }^{2}$ Regarding the reported 30 -day readmission rates for head and neck surgery, it ranges from 3.2 to $26.5 \%$, depending on the subsite, on the complexity of the surgery, and on a variety of factors. $2,3,7-9,11,12$

There is no data reported from European otorhinolaryngology - head and neck surgery departments about unplanned hospital readmission after head and neck surgery. Moreover, further understanding is needed about the risk factors associated with this. For that reason, the objective of the present study was to evaluate prospectively the incidence risk factors and causes associated with 30-day unplanned hospital readmission and visit to the emergency room (ER) after surgery for head and neck tumors.

\section{Materials and Methods}

A prospective, longitudinal, nonrandomized study was performed with the approval of the Ethics Committee of our Center (CCH-071719). Patients diagnosed with benign or malignant head and neck pathology, $\geq 18$ years old, undergoing inpatient or outpatient head and neck surgery in a tertiary university hospital between July of 2016 and July 2019 were included consecutively, excluding patients undergoing thyroid surgery (which is performed by general surgeons at our institution). Unplanned readmission was defined as "any unplanned readmission to the same or another hospital for a postoperative occurrence likely related to the principal surgical procedure within 30 days of the procedure". 9 Thus, hospital readmissions that occurred within 30 days of surgery and were planned or unrelated to the first surgical procedure were excluded. To achieve this, a follow-up protocol was conducted during the first 30 days after patient discharge to identify and classify any additional episodes of a visit to the emergency room or the need of readmission.

The demographic data (age, sex), comorbidities, diagnosis, stage in case of malignancy, imaging (computed tomography [CT], magnetic resonance imaging [MRI], ultrasound), the American Society of Anesthesiologists (ASA) classification, type of surgery, complications, outcomes after surgery, among others, were obtained during data collection. Readmission and the emergency room visit analysis was performed on this data.

Statistical analysis was performed with IBM SPSS Statistics for Windows, Version 20.0 (IBM Corp., Armonk, NY, USA). Quantitative variables are expressed as media \pm standard deviation (SD). Bivariate analysis using chi-squared and $t$ tests were used to analyze categorical and continuous variables, respectively. Univariate and multivariate logistic regression analysis was used to identify factors associated with 30-day readmission. Odds ratios (OR) and 95\% confidence intervals (95\%CIs) were calculated for the strength of association. All tests were 2 -sided, and a $p$-value $<0.05$ was considered statistically significant.

\section{Results}

A total of 834 patients, which represent $13.6 \%$ of the annual volume of patients of our department (2,096 surgeries per year and 6,288 surgeries in 3 years) met the inclusion criteria, 726 in the group of major surgery and 108 in the group of minor surgery. Of these, $573(68.7 \%)$ were male and $261(31.3 \%)$ were female. The age average was 59 years old $(\mathrm{SD}=14.80$; minimum 18; maximum 90). All demographic data are presented in - Table 1 . The patients had undergone a primary surgery of the head and neck region due to benign or malignant tumors, with a 30-day readmission rate for all causes of $7.9 \%$ for patients treated by a major surgery and of $0 \%$ for patients treated in the outpatient clinic for minor procedures, to a total rate of readmission of $6.8 \%$. The rate of a visit to the emergency room for all causes in the first 30 days was of $14 \%$ for patients treated by major surgery and of $2.7 \%$ for patients treated in the outpatient clinic (-Table 2).

In the group of major surgery, 42 (10.9\%) patients treated for benign tumors and 63 (18.4\%) patients treated for malignant tumors presented to the emergency room in the first 30 days after discharge ( $p=0.130$ ). Moreover, $18(4,6 \%)$ patients treated for benign tumors and $39(11,4 \%)$ treated for malignant tumors needed to be readmitted at the hospital to treat some complication in first 30 days after discharge $(p=0.054)$. The most common subsites were the larynx $(n=271)$, followed by parotid gland surgery $(n=127)$, skin cancer $(n=44)$, oral tongue $(n=32)$, and the oropharynx $(n=31)$.

In our patient population, $7.9 \%$ had unplanned hospital readmission, and $14.5 \%$ needed to visit the emergency room. When we evaluated the variables in the univariate and multivariate analysis, we only found statistical significance 

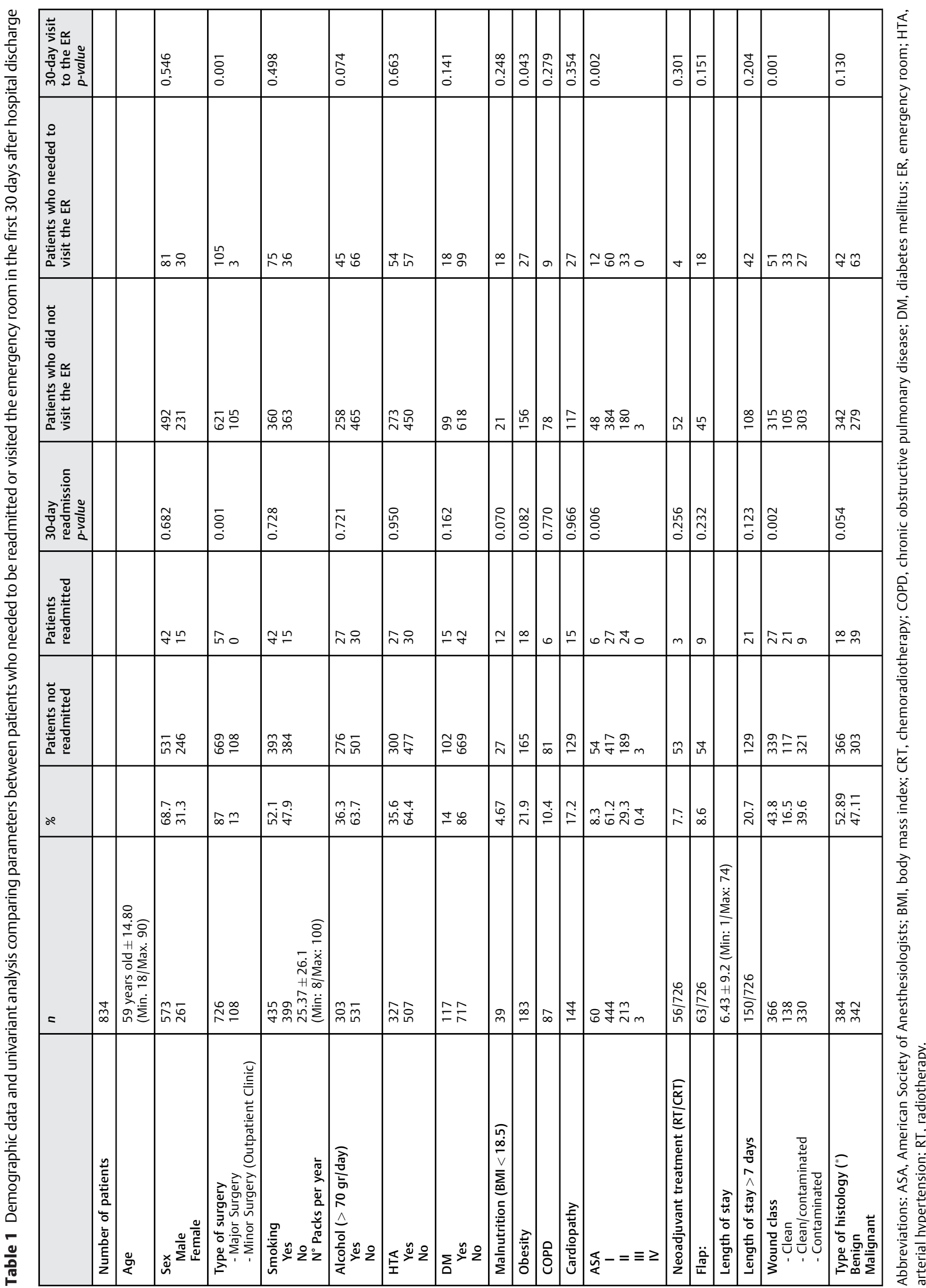
Table 2 Multivariant analysis of variables associated with readmission or visit to the emergency room

\begin{tabular}{|c|c|c|}
\hline & 30-day Readmission & 30-day visit to the ER \\
\hline Age & 0.430 (95\%Cl: - 0.651-1.579) & 0.218 (95\%Cl: - 0.651-1.579) \\
\hline $\begin{array}{l}\text { Sex } \\
\text { Male } \\
\text { Female }\end{array}$ & 0.858 (95\%Cl: - 0.308-- 0.181) & 0.639 (95\%Cl: - 0.249-- 0.111) \\
\hline $\begin{array}{l}\text { Type of surgery } \\
\text { - Major Surgery } \\
\text { - Minor Surgery (Outpatient Clin95\%Cl) }\end{array}$ & 0.001 (95\%Cl: - 0.784-- 0.677) & 0.001 (95\%Cl: - 0.724-- 0.607) \\
\hline $\begin{array}{l}\text { Smoking } \\
N^{\circ} \text { Packs per year }\end{array}$ & 0.181 (95\%Cl: - 0.455-- 0.301) & $0.385(95 \% \mathrm{Cl}:-0.496--0.193)$ \\
\hline Alcohol (> 70 gr-day) & 0.463 (95\%Cl: - 0.358-- 0.232) & 0.187 (95\%Cl: $-0.405-0.801)$ \\
\hline HTA & 0.483 (95\%Cl: - 0.388-- 0.260) & 0.537 (95\%Cl: - 0.323-0.169) \\
\hline DM & 0.676 (95\%Cl: - 0.147-0.154) & 0.663 (95\%Cl: - 0.084-0.221) \\
\hline Malnutrition (BMI < 18.5) & 0.009 (95\%Cl: - 0.015-0.065) & 0.021 (95\%Cl: - 0.323-- 0.270) \\
\hline Obesity & 0.720 (95\%Cl: - 0.237-- 0.110) & $0.980(95 \% \mathrm{Cl}:-0.178--0.037)$ \\
\hline COPD & 0.585 (95\%Cl: $-0.091-0.005)$ & 0.353 (95\%Cl: - 0.034-- 0.077) \\
\hline Chronic cardiac disease & 0.550 (95\%Cl: -0.156-- 0.052) & 0.776 (95\%Cl: - 0.097-0.018) \\
\hline $\begin{array}{l}\text { ASA } \\
\text { I } \\
\text { II } \\
\text { III } \\
\text { IV }\end{array}$ & 0.001 (95\%Cl: 0.216-0.384) & 0.008 (95\%Cl: $0.280-0.454)$ \\
\hline Flap: & 0.571 (95\%Cl: 0.340-0.769) & 0.613 (95\%Cl: - 0.707-- 0.270) \\
\hline Neoadjuvant treatment (RT-CRT) & 0.345 (95\%Cl: 0.179-0.467) & 0.412 (95\%Cl: $0.123-0.671)$ \\
\hline Length of stay $>7$ days & 0.067 (95\%Cl: 0.776-0.851) & 0.055 (95\%Cl: 0.840-0.919) \\
\hline $\begin{array}{l}\text { Wound class } \\
\text { - Clean } \\
\text { - Clean/contaminated } \\
\text { - Contaminated }\end{array}$ & 0.008 (95\%Cl: $0.071-0.237)$ & 0.006 (95\%Cl: - 0.022-0.202) \\
\hline $\begin{array}{l}\text { Type of histology } \\
\text { Benign } \\
\text { Malignant }\end{array}$ & 0.083 (95\%Cl: - 0.255-- 0.111) & $0.184(95 \% \mathrm{Cl}:-0.392-0.083)$ \\
\hline
\end{tabular}

Abbreviations: ASA, American Society of Anesthesiologists; BMI, body mass index; CRT, chemoradiotherapy; COPD, chronic obstructive pulmonary disease; DM, diabetes mellitus; ER, emergency room; HTA, arterial hypertension; RT, radiotherapy.

related to need the rate of readmission or visit to the emergency room according to the type of surgery (major versus minor procedures), ASA classification, or wound class. However, when we compared the results between the patients in the major surgery group who needed to be readmitted or who needed to visit the emergency room in the first 30 days after discharge and those who did not need, malignant histology $(p=0.006)$, ASA $(p=0.001)$, malnutrition $(p=0.002)$, and length of hospitalization $>7$ days $(p=0.016)$ were related to a major risk of readmission, while ASA $(p=0.001)$, malnutrition $(p=0.002)$ and length of hospitalization $>7$ days $(p=0.016)$ were related to a major risk of visit to the emergency room in the first 30 days after discharge (-Table $\mathbf{3}$ ). In contrast, other factors, such as the need of neoadjuvant treatment with radiotherapy or chemoradiotherapy, were not related with an increased risk of readmission $(p=0.256)$ or with visit to the emergency room $(p=0.301)$. Data about the type of major surgery performed, the cause of a visit to the emergency room, the most common cause of readmission or reintervention, and the type of reintervention can be seen on - Tables 4,5 , -supplementary Table S1, S2 and -supplementary Fig S1 (online only).

\section{Discussion}

Readmissions are often indicative of ineffective patient management, raising questions regarding the quality of care provided and generating significant costs for the healthcare system. ${ }^{13}$ Although some readmissions are unavoidable as a result of patient frailty or inevitable disease progression, others are preventable if patients receive the right care at the right time, reducing unnecessary readmissions.

Previous studies on head and neck cancer patients demonstrate the complex subset of these patients, who tend to be more frequently readmitted. Evaluating 155 total 
Table 3 Comparisons of factors between patients who needed to be readmitted or visited the emergency room in the major surgery group

\begin{tabular}{|l|l|l|}
\hline Variable & $\begin{array}{l}\text { Need of } \\
\text { readmission }(p)\end{array}$ & $\begin{array}{l}\text { Need of visit } \\
\text { to the ER }(p)\end{array}$ \\
\hline Gender & 0.113 & 0.679 \\
\hline Smoking & 0.195 & 0.234 \\
\hline Alcohol & 0.427 & 0.618 \\
\hline $\begin{array}{l}\text { Histology: malignant- } \\
\text { versus benign }\end{array}$ & 0.006 & 0.195 \\
\hline ASA & 0.001 & 0.001 \\
\hline $\begin{array}{l}\text { Malnutrition } \\
\text { (BMI }<\text { 18.5) }\end{array}$ & 0.002 & 0.001 \\
\hline Obesity & 0.516 & 0.790 \\
\hline DM & 0.513 & 0.856 \\
\hline HTA & 0.391 & 0.278 \\
\hline COPD & 0.729 & 0.361 \\
\hline Cardiopathy & 0.401 & 0.643 \\
\hline $\begin{array}{l}\text { Neoadjuvant treat- } \\
\text { ment RT/CRT }\end{array}$ & 0.163 & 0.413 \\
\hline $\begin{array}{l}\text { Length of hospitaliza- } \\
\text { tion }>\text { 7 days }\end{array}$ & 0.016 & 0.002 \\
\hline
\end{tabular}

Abbreviations: CRT, chemoradiotherapy; DM, diabetes mellitus; HTA, arterial hypertension; COPD, chronic obstructive pulmonary disease; RT, Radiotherapy.

laryngectomy patients treated at one institution, Graboyes et al. found a $26.5 \%$ 30-day readmission rate. ${ }^{11}$ Chaudhary et al. examined 1,518 elderly patients with oropharyngeal and laryngeal cancer from Medicare data in the USA and found that $14.1 \%$ of them were readmitted within the first 30 days of hospital discharge. ${ }^{14}$ Chen et al. performed a retrospective cohort study of head and neck cancer patients based on the Nationwide Readmissions Database from the USA and reported a $16.1 \%$ overall readmission rate, with the highest readmission rates for patients with laryngeal (21.8\%) and hypopharyngeal (29.6\%) cancer. ${ }^{15}$ Moreover, Bur et al. performed a retrospective analysis including data from the American College of Surgeons National Surgical Quality Improvement Program (NSQIP) database looking for clinical risk factors and complications related to unplanned hospital readmission, reporting a rate of $5.1 \%$ of unplanned readmission in 2 years. ${ }^{16}$ More recently, Baskin et al. highlighted the risk of return to the emergency room 30 days after surgery among patients who underwent head and neck surgery who needed to go to the intensive care unit. ${ }^{7}$ In another study, Goel et al. demonstrated a higher rate of readmission in patients who underwent head and nek reconstruction after ablative surgery. ${ }^{8}$ And $\mathrm{Wu}$ et al. in a study performed in Canada including patients who underwent head and neck surgery for benign and malignant disease, reported a rate of $3.2 \%$ of unplanned readmissions and of $8.4 \%$ of emergency room visits in the first 30 days after surgery. ${ }^{9}$ Similarly, our study reports a $7.9 \%$ overall readmission rate for patients treated for benign or malignant pathology, and of $11.4 \%$ for patients treated by malignant disease, with the highest readmission rates for patients with laryngeal cancer (31.5\%).

According to our data, the rate of unplanned readmission or the need to visit the emergency room during the first 30 days after hospital discharge was associated with major surgery, ASA classification status, and the type of wound, like in previous studies. ${ }^{16}$ Malignant histology, ASA classification status, malnutrition, and length of hospitalization $>7$ days were the factors related to an increased risk of readmission. The ASA classification status, malnutrition, and length of hospitalization $>7$ days were related to an increased risk of visit to the emergency room in the first 30 days after discharge. Previous data reported by Bur et al. demonstrated that the most common cause of unplanned readmissions after head and neck surgery were infectious, including wound infection or breakdown (24\%) and pneumonia (6.4\%). However, this study has some limitations because it examined readmissions starting from 30 days of the surgical date instead of the discharge date, which may underestimate the readmissions in the first 30 days after discharge for complex head and neck patients with prolonged hospital stays. ${ }^{16}$ Meanwhile, in our cohort, surgical site infection (2.87\%), wound seroma (1.07\%), pain $(2.15 \%)$, salivary fistula (1.07\%), or dysphagia (1.07\%) were the most common causes of unplanned readmission or visit to the emergency room for all patients treated by benign or malignant disease of the head and neck.

Chen et al. evaluated patient comorbidities and showed that valvular heart disease, rheumatoid arthritis or collagen vascular disease, liver disease, and hypothyroidism were independently associated with readmission. They hypothesize that most readmissions are due to infectious and wound healing issues and, for that reason, these comorbidities become particularly important. They suggest that rheumatoid arthritis and collagen vascular disease are markers of long-term steroid use and chronic immunosuppression, and that these comorbidities can be related to unplanned readmission. ${ }^{15}$ Similarly, Graboyes et al., in a previous study, found that long-term steroid use was associated with readmission in laryngectomy patients. ${ }^{11}$ Furthermore, hypothyroidism and liver disease can contribute to difficulties in wound healing. ${ }^{17,18}$ In our cohort, comorbidities such as diabetes, hypertension, obesity, COPD , or chronic cardiac disease were not associated with readmission. However, due to previously reported data, the need for an evidence-based risk stratification of the patients can be essential to improve decision-making and resource utilization. In this way, further investigation is needed to understand risk factors for unplanned hospital readmission after head and neck surgery. Strategies in future research need to include and report tools like the Charlson Comorbidity Index ${ }^{19}$ and to classify the patients routinely according to the Clavien and Dindo Classification. ${ }^{20}$

Another critical issue related to unplanned readmission is the cost to the healthcare system. Chen et al. report 30-day readmission costs of US $\$ 14,895$ ( $€ 16,860)$ on average for all payers in the USA, ${ }^{15}$ similarly to prior data reported by Chaudhary et al. on Medicare patients, which demonstrated that oropharyngeal and laryngeal cancer patients who were 
Table 4 Cases according to major or minor Surgery, 30-day readmission rate, 30-Day visit to the emergency room, type of histology, hospital readmission length of stay, and need of reintervention

\begin{tabular}{|c|c|c|}
\hline Variables & $n$ & $\%$ \\
\hline Major surgery & 726 & 87 \\
\hline 30-day readmission rate & 57 & 7.9 \\
\hline 30-day visit to the ER & 102 & 14 \\
\hline Minor surgery & 108 & 13 \\
\hline 30-day readmission rate & 0 & 0 \\
\hline 30-day visit to the ER & 3 & 2.7 \\
\hline \multicolumn{3}{|l|}{ Visit to the ER according to histology } \\
\hline Benign & $42 / 384$ & 10.9 \\
\hline Malignant & $60 / 342$ & 17.5 \\
\hline \multicolumn{3}{|l|}{ Readmission according to histology } \\
\hline Benign & $18 / 384$ & 4.6 \\
\hline Malignant & $39 / 342$ & 11.4 \\
\hline Hospital readmission length of stay & $\begin{array}{l}2 \pm 1.6 \\
\text { (Min: 1/Max: 17) }\end{array}$ & \\
\hline \multicolumn{3}{|l|}{ Need of reintervention by cause } \\
\hline Infection/abscess & 11 & \\
\hline Fistula & 4 & \\
\hline Intestinal perforation & 3 & \\
\hline Wound/skin dehiscence & 3 & \\
\hline Haemoptysis/oral bleeding & 3 & \\
\hline Total & 24 & $2.8 \%$ \\
\hline Cause & Procedure & \\
\hline Infection/abscess & Surgical drainage in all cases & \\
\hline Fistula & Pectoralis major flap in 3 cases, supraclavicular flap in 1 case. & \\
\hline Intestinal perforation & Surgical revision by general surgeons. & \\
\hline Wound/skin dehiscence & Skin suture in all cases. & \\
\hline Haemoptysis/oral bleeding & Surgical revision and hemostasis. & \\
\hline
\end{tabular}

readmitted had mean costs that were US\$15,123 (€17,120) higher than those who were not readmitted. ${ }^{14}$ Across European countries, healthcare providers are almost public, being necessary for the otorhinolaryngology-head and neck departments to evaluate their results and make some interventions aimed to improve them and to improve their savings, if necessary.

According to our data, the majority of readmissions are related to minor problems requiring only short hospital stays, and the significant financial impact over departments suggests that this is an area where some strategies can produce potential savings. In this way, avoiding preventable complication needs to be the primary objective in the postoperative period, translating this into a direct impact on the quality of life of our patients after discharge. Intervention over the risk of deep-vein thrombosis or venous thromboembolism, the correct use of antibiotics, implementation of protocols to assess the risk of dysphagia or silent aspiration aimed to prevent aspiration pneumonia, the cor- rect dosage of nonsteroid anti-inflammatory drugs or corticosteroids and the use of proton pump inhibitors needs to be implemented. Moreover, as proposed by Danino et al. some possible ways to improve the rate of readmission can be a better patient or caregiver education related to possible complications, which can be done using written information describing postoperative symptoms and alarm signs, giving contact information to solve doubts, providing adequate analgesia to improve the quality of patient care, administering antibiotics in cases in which they may be needed, including a postoperative follow-up telephone call, and improving the training of emergency doctors in postoperative care of head and neck tumor patients to manage nonemergency complication, preventing the need for reattendance or potential readmission. ${ }^{5}$

Finally, a limitation in our study can be the small sample size compared with previous retrospective studies and the lack of cost-related analysis. For that reason, we decide to expand the duration of our study to evaluate and report more 
Table 5 Types of surgery performed and the rate of visit to the ER or of readmission in the first 30 days

\begin{tabular}{|c|c|c|c|c|c|}
\hline Major Surgery & Visit to the ER & $\begin{array}{l}\text { Need of } \\
\text { Readmision }\end{array}$ & Minor Surgery & Visit to the ER & $\begin{array}{l}\text { Need of } \\
\text { Readmision }\end{array}$ \\
\hline $\begin{array}{l}\text { Laser surgery of the } \\
\text { larynx without neck } \\
\text { dissection }\end{array}$ & $12 / 184$ & $6 / 184$ & Adenectomy & $2 / 36$ & $0 / 36$ \\
\hline $\begin{array}{l}\text { Laser surgery of the } \\
\text { supraglottis with neck } \\
\text { dissection }\end{array}$ & $12 / 38$ & $9 / 38$ & Tracheostomy closure & $0 / 15$ & $0 / 15$ \\
\hline $\begin{array}{l}\text { Laser surgery of the } \\
\text { hypopharynx }\end{array}$ & $6 / 25$ & $6 / 25$ & Sebaceous cyst resection & $0 / 12$ & $0 / 12$ \\
\hline $\begin{array}{l}\text { Cricopharyngeal laser } \\
\text { miotomy }\end{array}$ & $0 / 1$ & $0 / 1$ & Oral leucoplakia biopsy & $0 / 12$ & $0 / 12$ \\
\hline Total laryngectomy & $10 / 49$ & $5 / 49$ & Oral papilloma resection & $0 / 12$ & $0 / 12$ \\
\hline Oropharyngectomy & $6 / 31$ & $3 / 31$ & Facial palsy outpatient surgery & $1 / 9$ & $0 / 9$ \\
\hline Oral tongue cancer & $2 / 32$ & $1 / 32$ & Oral angioma resection & $0 / 6$ & $0 / 6$ \\
\hline Lip cancer resection & $1 / 14$ & $0 / 14$ & Vermellectomy & $0 / 6$ & $0 / 6$ \\
\hline $\begin{array}{l}\text { Tumor of the cheek } \\
\text { mucosa }\end{array}$ & $0 / 5$ & $0 / 5$ & Small cervical lipoma & $0 / 3$ & $0 / 3$ \\
\hline Floor of the mouth tumor & $1 / 10$ & $1 / 10$ & & & \\
\hline $\begin{array}{l}\text { Tumor of the infrastruc- } \\
\text { ture of the maxilla }\end{array}$ & $1 / 3$ & $0 / 3$ & & & \\
\hline Salvage neck dissection & $9 / 24$ & $6 / 24$ & & & \\
\hline Branquial cyst surgery & $2 / 30$ & $2 / 30$ & & & \\
\hline $\begin{array}{l}\text { Thyroglossal duct cyst } \\
\text { resection }\end{array}$ & $3 / 24$ & $2 / 24$ & & & \\
\hline Cervical dermoid cyst & $1 / 10$ & $0 / 10$ & & & \\
\hline Big cervical lipoma & $1 / 10$ & $1 / 10$ & & & \\
\hline $\begin{array}{l}\text { Submaxilectomy for be- } \\
\text { nign tumors or lithiasis }\end{array}$ & $6 / 22$ & $6 / 22$ & & & \\
\hline $\begin{array}{l}\text { Submaxilectomy for ma- } \\
\text { lignant tumors }\end{array}$ & $1 / 3$ & $1 / 3$ & & & \\
\hline $\begin{array}{l}\text { Parotidectomy for benign } \\
\text { tumors }\end{array}$ & $24 / 106$ & $4 / 106$ & & & \\
\hline $\begin{array}{l}\text { Parotidectomy for malig- } \\
\text { nant tumors }\end{array}$ & $2 / 21$ & $1 / 21$ & & & \\
\hline Skin cancer surgery & $2 / 44$ & $1 / 44$ & & & \\
\hline Rhinectomy & $0 / 1$ & $0 / 1$ & & & \\
\hline $\begin{array}{l}\text { Microsurgery of the } \\
\text { larynx }\end{array}$ & $1 / 26$ & $1 / 26$ & & & \\
\hline Secondary provox & $2 / 6$ & $2 / 6$ & & & \\
\hline Panendoscopy & $0 / 8$ & $0 / 8$ & & & \\
\hline
\end{tabular}

Abbreviation: ER, emergency room.

extensive data in the future to try to define strategies to avoid readmission for head and neck cancer surgery patients and perform a cost-related analysis.

\section{Conclusion}

Major surgery, ASA status and the type of wound are conditions related to unplanned readmission or visit to the emergency room in the first 30 days after discharge. The most common associated causes are infections or wound complications. In this way, an evidence-based risk stratification of the patients can be an essential tool to improve decision-making and resource utilization, and some educational strategies can provide ways to improve the rate of readmission, reducing the amount of money expended by healthcare systems.

Conflict of Interests

The authors have no conflict of interests to declare. 
110 Unplanned Hospital Readmission and Visit to the Emergency Room Chiesa-Estomba et al.

\section{References}

1 National Health Expenditures 2014 Highlights. December 3, 2015. Accessed January 11, 2016 at: https://www.cms.gov/Research-Statistics-Data-and-Systems/Statistics-Trends-and-Reports/NationalHealthExpendData/downloads/highlights.pdf

2 Graboyes EM, Liou TN, Kallogjeri D, Nussenbaum B, Diaz JA. Risk factors for unplanned hospital readmission in otolaryngology patients. Otolaryngol Head Neck Surg 2013;149(04):562-571

3 Kassin MT, Owen RM, Perez SD, et al. Risk factors for 30-day hospital readmission among general surgery patients. J Am Coll Surg 2012;215(03):322-330

4 Dziegielewski PT, Boyce B, Manning A, et al. Predictors and costs of readmissions at an academic head and neck surgery service. Head Neck 2016;38(Suppl 1):E502-E510

5 Danino JF, Taylor T, Metcalfe CW, Muzaffar SJ, Sinha A. Readmission rates and financial penalties after ear, nose and throat surgery: how can we improve? Br J Hosp Med (Lond) 2015;76(11):655-657

6 Luryi AL, Chen MM, Mehra S, Roman SA, Sosa JA, Judson BL. Hospital readmission and 30-day mortality after surgery for oral cavity cancer: Analysis of 21,681 cases. Head Neck 2016;38 (Suppl 1):E221-E226

7 Baskin RM, Zhang J, Dirain C, et al. Predictors of returns to the emergency department after head and neck surgery. Head Neck 2018;40(03):498-511

8 Goel AN, Raghavan G, St John MA, Long JL. Risk Factors, Causes, and Costs of Hospital Readmission After Head and Neck Cancer Surgery Reconstruction. JAMA Facial Plast Surg 2019;21(02):137-145

$9 \mathrm{Wu} \mathrm{V}$, Hall SF. Rates and causes of 30-day readmission and emergency room utilization following head and neck surgery. J Otolaryngol Head Neck Surg 2018;18(47):36

10 Lucas DJ, Pawlik TM. Readmission after surgery. Adv Surg 2014; 48:185-199

11 Graboyes EM, Yang Z, Kallogjeri D, Diaz JA, Nussenbaum B. Patients undergoing total laryngectomy: an at-risk population for 30-day unplanned readmission. JAMA Otolaryngol Head Neck Surg 2014;140(12):1157-1165

12 American College of Surgeons. User guide for the 2014 American College of Surgeons National Surgical Quality Improvement Program participant use data file. October 2015. Accessed December 29, 2015. https://www.facs.org/ /media//files/quality\% 20programs/nsqip/nsqip_puf_userguide_2014.ashx

13 Halfon P, Eggli Y, Prêtre-Rohrbach I, Meylan D, Marazzi A, Burnand B. Validation of the potentially avoidable hospital readmission rate as a routine indicator of the quality of hospital care. Med Care 2006;44(11):972-981

14 Chaudhary H, Stewart CM, Webster K, et al. Readmission following primary surgery for larynx and oropharynx cancer in the elderly. Laryngoscope 2017;127(03):631-641

15 Chen MM, Orosco RK, Harris JP, et al. Predictors of readmissions after head and neck cancer surgery: A national perspective. Oral Oncol 2017;71:106-112

16 Bur AM, Brant JA, Mulvey CL, et al. Association of Clinical Risk Factors and Postoperative Complications With Unplanned Hospital Readmission After Head and Neck Cancer Surgery. JAMA Otolaryngol Head Neck Surg 2016;142(12):1184-1190

17 Zimmermann E, Ribas-Filho JM, Malafaia O, et al. Tracheal suture in rats with hypothyroidism: wound healing study. Acta Cir Bras 2009;24(04):282-289

18 Karalis M, Pavlidis TE, Psarras K, et al. Effect " of experimentally induced liver cirrhosis on wound healing of the post-extraction tooth socket in rats. Eur Surg Res 2008;40(02):190-196

19 Charlson ME, Pompei P, Ales KL, MacKenzie CR. A new method of classifying prognostic comorbidity in longitudinal studies: development and validation. J Chronic Dis 1987;40(05):373-383

20 Dindo D, Demartines N, Clavien PA. Classification of surgical complications: a new proposal with evaluation in a cohort of 6336 patients and results of a survey. Ann Surg 2004;240(02): 205-213 